\title{
THE ROLE OF CRYOPRESERVATION IN THE BIOMECHANICAL PROPERTIES OF THE INTERVERTEBRAL DISC
}

\author{
S.K.L. Lam ${ }^{1,2}$, S.C.W. Chan ${ }^{1,3}$, V.Y.L Leung ${ }^{1}$, W.W. Lu ${ }^{1}$, K.M.C. Cheung ${ }^{1}$ and K.D.K. Luk ${ }^{1 *}$ \\ ${ }^{1}$ Department of Orthopaedics and Traumatology, University of Hong Kong, Pokfulam, \\ Hong Kong, SAR, China \\ ${ }^{2}$ Institute of Medical and Biological Engineering, University of Leeds, Leeds, U.K. \\ ${ }^{3}$ Institute of Surgical Technology and Biomechanics, University of Bern, Bern, Switzerland
}

\begin{abstract}
Implantation of intervertebral disc (IVD) allograft or tissue engineered disc constructs in the spine has emerged as an alternative to artificial disc replacement for the treatment of severe degenerative disc disease (DDD). Establishment of a bank of cryopreserved IVD allografts enables size matching and facilitates logistics for effective clinical management. However, the biomechanical properties of cryopreserved IVDs have not been previously reported. This study aimed to assess if cryopreservation with different concentrations of cryopreservant agents (CPA) would affect the dynamic viscoelastic properties of the IVD. Whole porcine lumbar IVDs $(n=40)$ were harvested and processed using various concentrations of CPA, $0 \% \mathrm{CPA}, 10 \% \mathrm{CPA}$ and $20 \% \mathrm{CPA}$. The discs were cryopreserved using a stepwise freezing protocol and stored in liquid nitrogen. After four weeks of storage, the cryopreserved IVDs were quickly thawed at $37{ }^{\circ} \mathrm{C}$ for dynamic viscoelastic testing. The apparent modulus, elastic modulus ( $\left.G^{\prime}\right)$, viscous modulus (G') and loss modulus $\left(\mathrm{G}^{\prime} / \mathrm{G}^{\prime}\right)$ were calculated and compared to a fresh control group. Cryopreserved IVD without cryopreservants was significantly stiffer than the control. In the dynamic viscoelastic testing, cryopreservation with the use of CPA was able to preserve both G' and G" of an IVD. No significant differences were found between fresh IVD and IVD cryopreserved with $10 \%$ CPA or 20 $\%$ CPA. This study demonstrated that CPAs at an optimal concentration could preserve the mechanical properties of the IVD allograft and can provide further credence for the application of long-term storage of IVD allografts for disc transplantation or tissue engineered construct applications.
\end{abstract}

Keywords: Intervertebral disc, allograft, transplantation, cryopreservation, biomechanics.

\footnotetext{
*Address for correspondence:

Keith D.K. Luk

Department of Orthopaedics and Traumatology

Queen Mary Hospital, The University of Hong Kong

Pokfulam, Hong Kong SAR, China
}

Telephone Number: +852 22554254

FAX Number: +852 28174392

E-mail: hrmoldk@hku.hk

\section{Introduction}

Low back pain is a debilitating condition with tremendous socioeconomic and health-care expenditure (Hart et al., 1995; Andersson, 1999; Deyo et al., 2006; Gray et al., 2006; Katz, 2006; Freburger et al., 2009). Degenerative disc disease (DDD) is an etiological factor associated with lower back pain (Luoma et al., 2000; Bendix et al., 2008; de Schepper et al., 2010). Currently, the most common treatment for DDD is spinal fusion (Fritzell et al., 2001; Brox et al., 2003). However, fusion of the vertebral segments restricts spinal motion, which may increase stress and motion at the adjacent segments; thereby, contributing to the degenerative process at adjacent levels that may become symptomatic and necessitate surgical intervention (Ghiselli et al., 2004; Hilibrand and Robbins, 2004; Park et al., 2004; Hoogendoorn et al., 2008).

To counter the effects of spinal fusion and preserve motion, the uses of intervertebral disc (IVD) artificial implant devices have been advocated. However, the success of an artificial disc implant relies heavily on the design and positioning of the implant in the interbody space to achieve the required biomechanics that would recreate the natural properties of the human disc (Huang et al., 2003; Lee and Langrana, 2004). Studies of artificial disc implants have suggested that the total disc replacement causes permanent changes in the kinematics of the spine and cannot fully restore normal mobility (Dooris et al., 2001; Tournier et al., 2007; Rohlmann et al., 2009). Such permanent changes in the kinematics of the spine can cause instability and increase stress forces at the adjacent segments that may also contribute to the degenerative process at those levels (Lee and Goel, 2004; Lee and Langrana, 2004).

As an alternative to artificial disc replacement, intervertebral disc allograft transplantation has been developed (Olson et al., 1991; Frick et al., 1994; Matsuzaki et al., 1996; Luk et al., 2003) with noted satisfactory clinical outcomes in humans at five-year follow-up (Ruan et al., 2007; Luk and Ruan, 2008). However, appropriate size-matching of the allograft to the recipient site is one of the key factors in ensuring transplantation success. As such, preserving and storing allograft IVD of different sizes in an IVD bank is essential before the procedure can be popularised. Cryopreservation is one method that can enable tissue storage. It is used widely for preserving sperm, ovum, and even embryo. However, some studies have reported that freezing the IVD can cause permanent changes to its mechanical properties (Flynn et al., 1990; Bass et al., 1997; Gleizes et al., 1998). Other researchers have shown that sheep IVD 


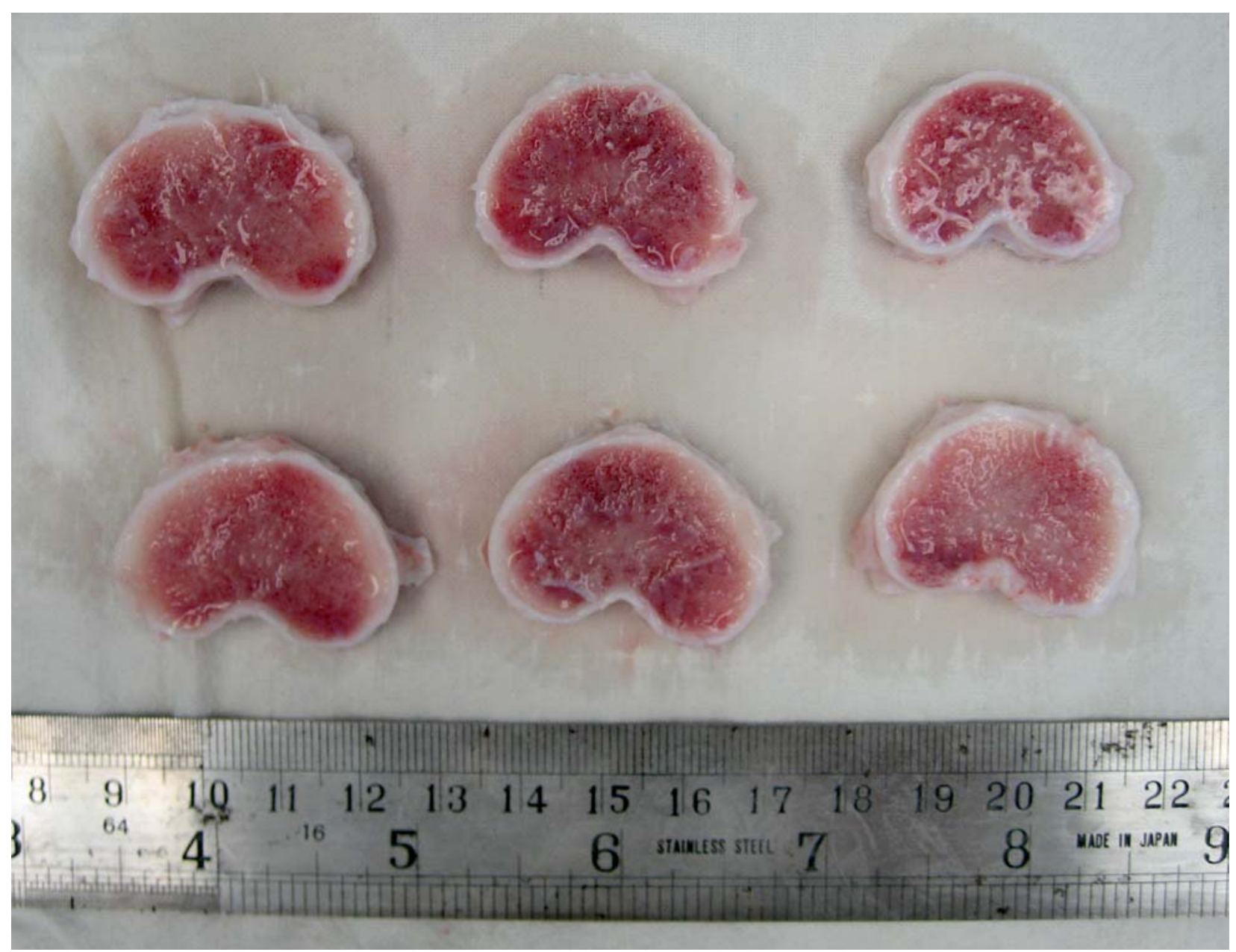

Fig. 1. Porcine lumbar intervertebral disc allografts.

frozen without cryopreservants for a period of three months resulted in irreversible deterioration of the biomechanical properties of the IVD (Gleizes et al., 1998). Likewise, some authors have contended that frozen storage permanently alters the permeability and creep behaviour of the porcine IVD, while studies on the human IVD revealed that a typical freezing protocol did not significantly alter matters (Dhillon et al., 2001). Furthermore, freeze-drying the IVD may compromise the stiffness of the spinal segments to a significantly greater extent than deep-freezing because the water content within the matrix of the disc is removed through the lyophilisation process of freeze-drying (Flynn et al., 1990).

Long-term storage of IVD allografts of different sizes in an IVD bank is an essential component for IVD allograft transplantation. The use of cryopreservant agent (CPA) is vital to the safe preservation of the IVD (Matsuzaki et al., 1996; Bass et al., 1997). There is no consensus in the literature on a cryopreservation protocol that can best retain the whole IVD allograft. The effect of different strengths of CPA on the physical properties of the composite is also not known. It is important that the mechanical properties of the IVD allograft implant following cryopreservation are characterised to see if it can retain similar properties as a normal IVD because it has been established that the mismatch of mechanical properties between the implant and the host tissue can be detrimental to the performance of the implant (Bao et al., 1996). Moreover, the difference in mechanical properties may change the pattern of loading through the spine and can cause changes to the kinematics as well as degeneration of the facet joints (Dooris et al., 2001). Therefore, the objective of this study was to investigate the effects of CPA concentration on the biomechanical properties of the IVD allograft.

\section{Materials and Methods}

\section{Porcine disc harvest}

Porcine lumbar discs (L1 to L6) $(n=40)$ were harvested from 9 pigs (weight range $=37$ to $42 \mathrm{~kg}$ ) that were freshly sacrificed with an injection of an overdose of pentobarbitone $(200 \mathrm{mg} / \mathrm{kg})$. After removal of the surrounding muscles and posterior elements, an osteotomy was made at the endplates approximately $10 \mathrm{~mm}$ above and below the disc. The endplate-annulus fibrosus-nucleus pulposus composite was removed en-bloc. A high-speed burr (Stryker, Mahwah, NJ, USA) was then utilised to further trim down the bony endplate to a thickness of 1-2 $\mathrm{mm}$ in a manner avoiding the development of fractures. The whole discs were kept in Hank's buffered saline solution (HBSS) with $50 \mathrm{mmol}$ sodium citrate (Sigma-Aldrich, St. Louis, MO, USA), $1 \%$ Penicillin/Streptomycin, and $0.4 \%$ 


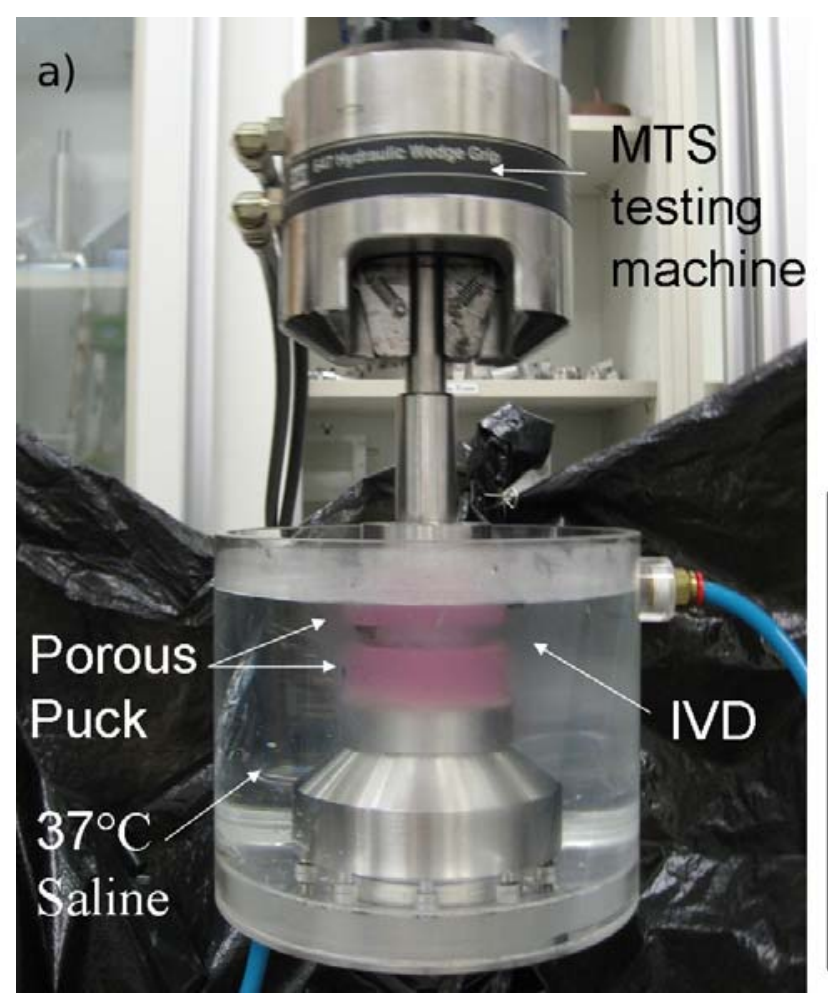

b)

Fig. 2. Mechanical testing setup for intervertebral disc allograft.

fungizone (Gibco, Invitrogen, Carlsbad, CA, USA) during processing (Chan et al., 2010). The endplates surfaces were lavaged with saline solution using the Pulsavac ${ }^{\mathrm{TM}}$ wound debridement irrigation system (Zimmer, Münsingen, Switzerland) to remove cutting debris and clotted blood (Gantenbein et al., 2006). The discs had a mean length, width and height of $30.1 \pm 4.3 \mathrm{~mm}, 23.3 \pm 3.9 \mathrm{~mm}$, and 7.3 $\pm 0.7 \mathrm{~mm}$, respectively (Fig. 1 ).

\section{Intervertebral disc allograft cryopreservation}

Corneal Potassium Tes 2 (CPTES2) solution was used as the CPA carrier solution. The CPTES2 contained the following: $\mathrm{Na}^{+} 31 \mathrm{mmol} / \mathrm{L}, \mathrm{K}+100 \mathrm{mmol} / \mathrm{L}, \mathrm{Mg}^{2+} 1$ $\mathrm{mmol} / \mathrm{L}, \mathrm{Ca}^{2+} 1 \mathrm{mmol} / \mathrm{L}, \mathrm{Cl}^{-} 62 \mathrm{mmol} / \mathrm{L}, \mathrm{HCO}_{3}^{-} 30 \mathrm{mmol} / \mathrm{L}$, $\mathrm{H}_{2} \mathrm{PO}_{4}^{-} 1 \mathrm{mmol} / \mathrm{L}, \mathrm{SO}_{4}{ }^{2-} 1 \mathrm{mmol} / \mathrm{L}$, glucose $5 \mathrm{mmol} / \mathrm{L}$, TES $100 \mathrm{mmol} / \mathrm{L}$ (all chemicals from Sigma-Aldrich). The discs were randomly cryopreserved in various concentration of CPA as follows: (1) $0 \%$ CPA (CPTES2 solution only) ( $n=$ 10); (2) $10 \%$ CPA (10\% DMSO in CPTES2 solution) (n $=10)$; and (3) $20 \%$ CPAs (10\% DMSO + $10 \%$ Propylene glycol (PPG) (Sigma-Aldrich USA) in CPTES2 solution) $(n=10)$. The discs were incubated with the CPA for $2 \mathrm{~h}$ at $4{ }^{\circ} \mathrm{C}$, frozen stepwise to $-80^{\circ} \mathrm{C}$ at $-0.3^{\circ} \mathrm{C} / \mathrm{min}$ overnight and then stored in liquid nitrogen for four weeks (Chan et al., 2010). Before the biomechanical testing, all IVD allografts were thawed quickly at $37^{\circ} \mathrm{C}$ in a saline bath until all the CPA had melted and testing were performed within $30 \mathrm{~min}$ after the IVD allografts were taken out of the liquid nitrogen. Fresh untreated IVD from 9 animals were used as controls $(n=10)$. All specimens were examined for any damages to the endplates following cryopreservation and were radiographed (Faxitron X-Ray Corporation, Wheeling, IL, USA). The X-rays were digitised using an $\mathrm{x}$-ray digitiser (Vidar, Herndon, VA, USA) with a resolution of $2800 \times 2507$ pixels. The crosssectional area of the IVD were measured using Image Pro Plus (Media Cybernetics, Bethesda, MD, USA), and disc cross-sectional area was computed as an ellipse using the formula $\pi / 4 \times \mathrm{d} 1 \times \mathrm{d} 2$, where $\mathrm{d} 1$ and $\mathrm{d} 2$ were the lateral and anteroposterior widths.

\section{Mechanical testing}

Non-destructive uniaxial compression testing was performed using MTS 858 Bionix Testing Machine (MTS System Inc., Minneapolis, MN, USA). Samples were placed between two porous platens (pore size $20 \mu \mathrm{m}$ ) inside a $37^{\circ} \mathrm{C}$ normal saline $(0.15 \mathrm{~mol} / \mathrm{L} \mathrm{NaCl})$ bath as shown in Fig. 2. All samples were loaded with a basal compressive load of $10 \mathrm{~N}$ so as to maintain contact between the puck and the samples during the testing.

\section{Dynamic mechanical testing}

The viscoelastic properties of the cryopreserved IVD were investigated using the method described by Miyamoto et al. (Miyamoto et al., 2006). Preconditioning was performed by applying 10 sinusoidal strain cycles with an amplitude of $10 \%$ at $1 \mathrm{~Hz}$. After a 3 min recovery from preconditioning the IVDs were tested using 6 frequencies of uniaxial compression loading $(0.05 \mathrm{~Hz}, 0.1 \mathrm{~Hz}, 0.2 \mathrm{~Hz}$, $0.5 \mathrm{~Hz}, 1 \mathrm{~Hz}$ and $2 \mathrm{~Hz}$ ) and compressed with $10 \%$ strain amplitude. Each frequency test was performed using one cycle of sinusoidal strain followed by 3-minute recovery (Fig. 3a). An elastic modulus (G'), a viscous modulus (G') and a loss tangent (G'/G') were determined. G' represents the elastic behaviour with its ability to store deformational energy and G" represents viscous behaviour 

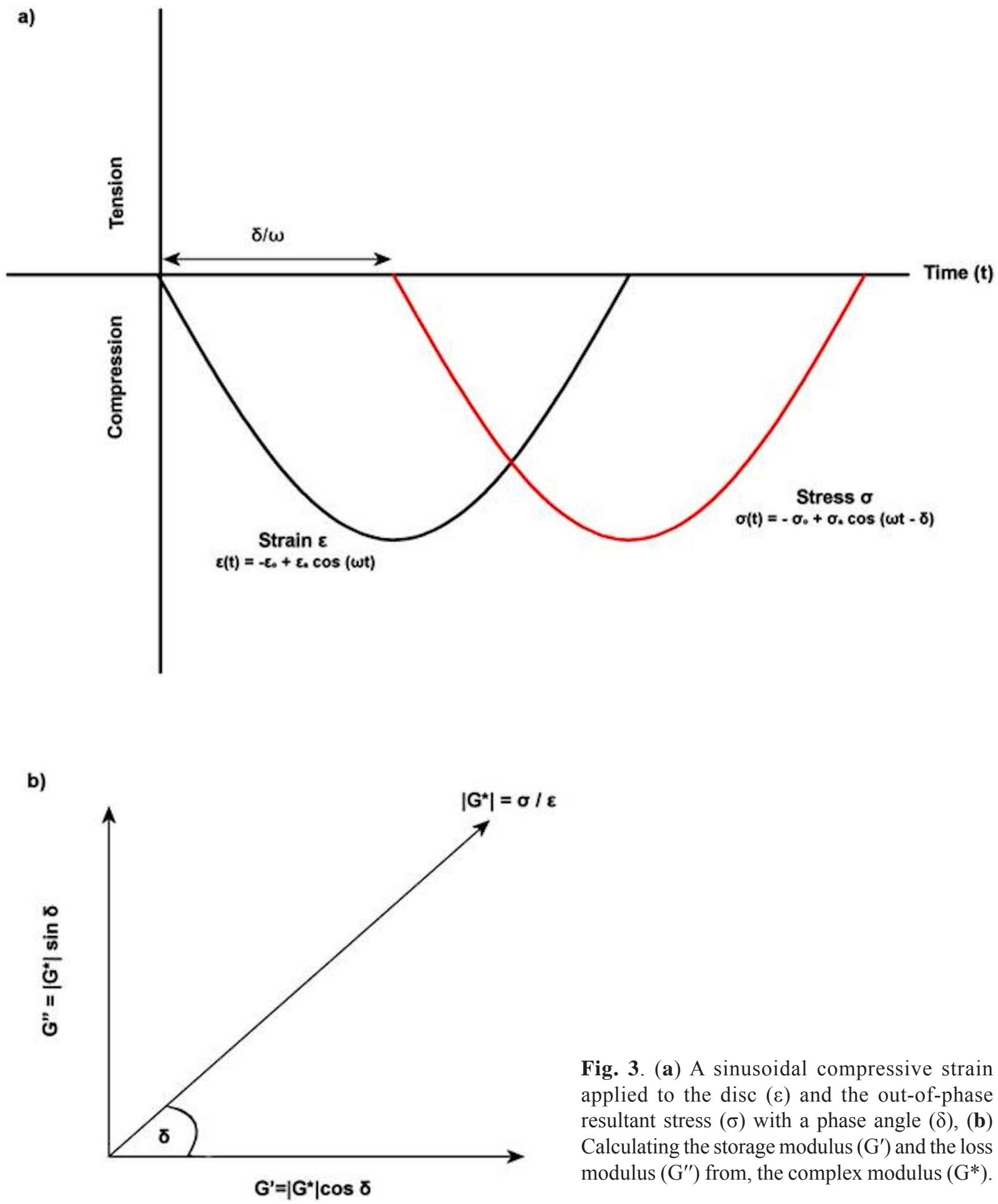

Fig. 3. (a) A sinusoidal compressive strain applied to the disc $(\varepsilon)$ and the out-of-phase resultant stress $(\sigma)$ with a phase angle $(\delta),(\mathbf{b})$ Calculating the storage modulus $\left(\mathrm{G}^{\prime}\right)$ and the loss modulus $\left(G^{\prime \prime}\right)$ from, the complex modulus $\left(G^{*}\right)$.

with the dissipation of energy during deformation in the IVD (Tanaka et al., 2002). The complex modulus (G*) was determined by $\left|G^{*}\right|=\sigma / \varepsilon$, where stress $\sigma=$ force $(F)$ / cross-sectional area (A), strain $\varepsilon=$ change in disc height $(\Delta \mathrm{DH}) /$ disc height $(\mathrm{DH})$ (Miyamoto et al., 2006). G' was determined by $G^{\prime}=\left|G^{*}\right| \cos \delta, G^{\prime \prime}$ by $G^{\prime \prime}=\left|G^{*}\right| \sin \delta$, and G'/G' by $\tan \delta=G^{\prime \prime} / G^{\prime}$ (Fig. 3b).

\section{Compression testing}

The stiffness of the cryopreserved IVD was characterised. Following the dynamic compression testing, a slow compression ramp $(0.5 \mathrm{~mm} / \mathrm{s})$ of maximum load $200 \mathrm{~N}$ of axial compression was applied (Costi et al., 2002). Stiffness was calculated using linear regression for the mode of loading and was defined as the slope of the loaddisplacement curve over a defined range of load (Costi et al., 2002).

\section{Statistical analysis}

One-way ANOVA followed by LSD post-hoc test was used to evaluate the statistical difference in the elastic, viscous, loss tangent and stiffness between different treatment groups. A $p$ value $<0.05$ was considered to be statistically significant. 

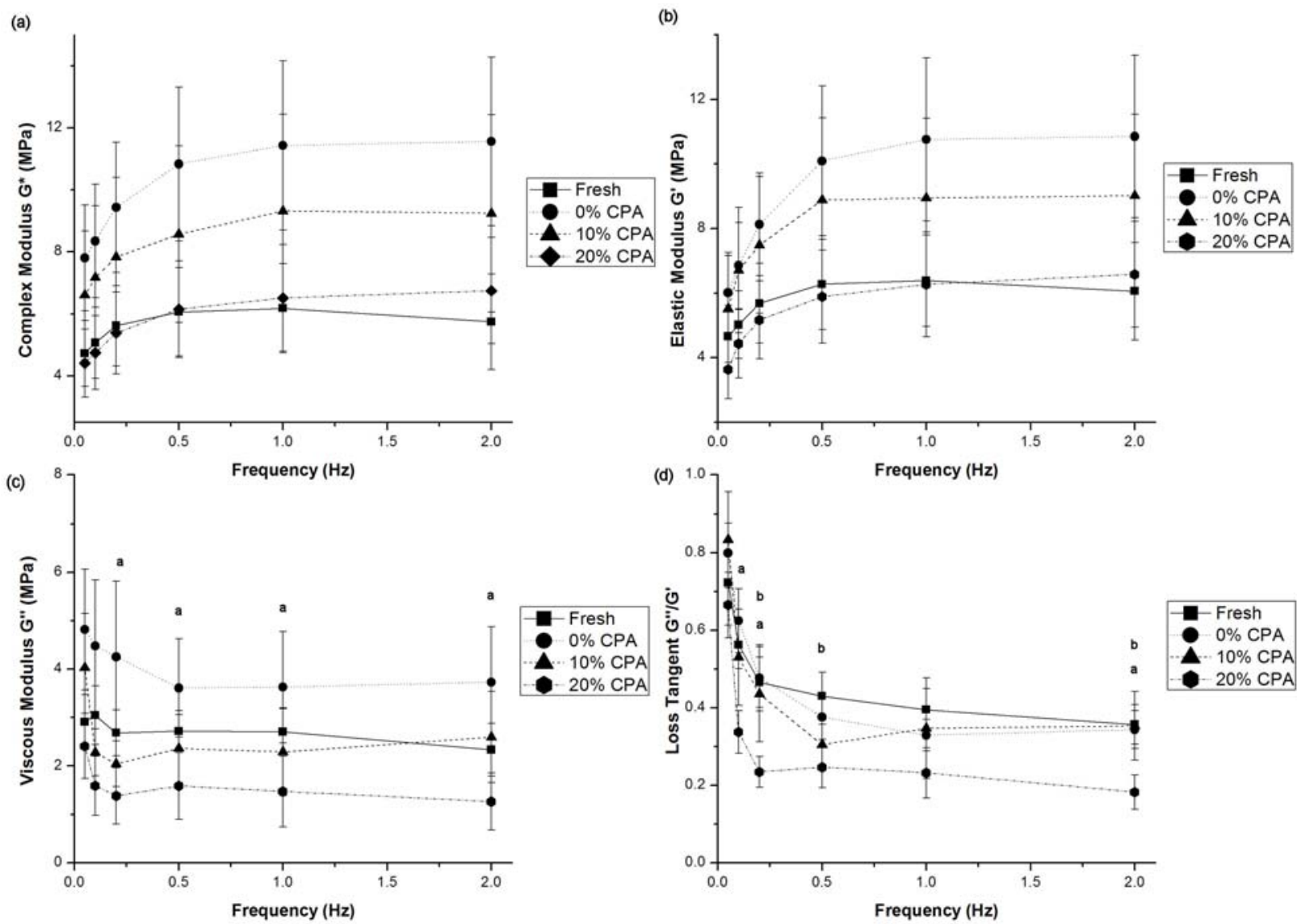

Fig. 4. Effects of cryopreservation (CPA) concentration on the apparent modulus of the porcine intervertebral disc (mean $\pm \mathrm{SEM}) .{ }^{\text {a }}$ denotes statistical significance at $p<0.05$.

\section{Results}

\section{Dynamic mechanical testing}

The G*, G', G" and G'/G' of the fresh control and different treatment groups over the range of testing frequencies are presented in Fig. 4.

G' was observed to increase with increasing frequency rate. The range of the G' for the fresh control was 4.66 $\pm 0.96 \mathrm{MPa}$ at $0.05 \mathrm{~Hz}$ to $6.39 \pm 1.41 \mathrm{MPa}$ at $1 \mathrm{~Hz}$, while the G' range of the $10 \%$ CPA group and $20 \%$ CPA group was $5.51 \pm 1.65 \mathrm{MPa}$ at $0.05 \mathrm{~Hz}$ to $9.02 \pm 2.52 \mathrm{MPa}$ at 2 $\mathrm{Hz}$ and $3.64 \pm 0.91 \mathrm{MPa}$ at $0.05 \mathrm{~Hz}$ to $6.58 \pm 1.64 \mathrm{MPa}$ at 2 $\mathrm{Hz}$, respectively. The $0 \% \mathrm{CPA}$ group recorded the highest G' properties, $6.02 \pm 1.24 \mathrm{MPa}$ at $0.05 \mathrm{~Hz}$ to $10.85 \pm 2.52$ $\mathrm{MPa}$ at $2 \mathrm{~Hz}$. The $20 \% \mathrm{CPA}$ group retained the closest G' properties to the fresh IVD group, but no statistical significant differences in the G' properties were detected among the different groups across the frequencies.

The G" properties were observed to decrease with increasing frequency rate. No statistical significant differences in G" properties were detected between the fresh control group and the treatment groups. The G" range of the fresh control was $3.05 \pm 0.60 \mathrm{MPa}$ at $0.1 \mathrm{~Hz}$ to 2.33 $\pm 0.55 \mathrm{MPa}$ at $2 \mathrm{~Hz}$ while the $10 \% \mathrm{CPA}$ group recorded a G" range of $4.03 \pm 1.12 \mathrm{MPa}$ at $0.05 \mathrm{~Hz}$ to $2.04 \pm 0.47$ $\mathrm{MPa}$ at $0.2 \mathrm{~Hz}$. The G" properties of the $20 \% \mathrm{CPA}$ group range from $2.41 \pm 0.67 \mathrm{MPa}$ at $0.05 \mathrm{~Hz}$ to $1.27 \pm 0.59 \mathrm{MPa}$ at $2 \mathrm{~Hz}$. The $0 \% \mathrm{CPA}$ recorded the highest G" range of $4.81 \pm 1.24 \mathrm{MPa}$ at $0.05 \mathrm{~Hz}$ to $3.61 \pm 1.02 \mathrm{MPa}$ at $0.5 \mathrm{~Hz}$. A statistically significant difference was noted between 0 $\%$ CPA and $20 \%$ CPA groups in the G" for $0.2 \mathrm{~Hz}$ ( $p=$ $0.026), 0.5 \mathrm{~Hz}(p=0.04), 1 \mathrm{~Hz}(p=0.016)$ and $2 \mathrm{~Hz}(p=$ $0.026)$.

A decreasing trend was observed in the $\mathrm{G}^{\prime} / \mathrm{G}^{\prime}$ factor with increasing frequency in all the groups. The $G " / G^{\prime}$ factor range in the fresh control was $0.94 \pm 0.13$ at $0.05 \mathrm{~Hz}$ to $0.30 \pm 0.09$ at $0.5 \mathrm{~Hz}$ while the G'/G' factor in the $10 \%$ CPA group and $20 \%$ CPA group was $0.83 \pm 0.12$ at $0.05 \mathrm{~Hz}$ to $0.30 \pm 0.05$ at $0.5 \mathrm{~Hz}$ and $0.66 \pm 0.08$ at $0.05 \mathrm{~Hz}$ to 0.18 \pm 0.04 at $2 \mathrm{~Hz}$, respectively. While the $0 \% \mathrm{CPA}$ group had a G"/G' factor range of $0.79 \pm 0.07$ at $0.05 \mathrm{~Hz}$ to $0.33 \pm 0.04$ at $1 \mathrm{~Hz}$. Statistically significant differences were observed in the loss modulus where there were differences between $0 \% \mathrm{CPA}$ and $20 \% \mathrm{CPA}$ at $0.1 \mathrm{~Hz}(p=0.009), 0.2 \mathrm{~Hz}(p$ $=0.024)$ and $2 \mathrm{~Hz}(p=0.032)$. Furthermore, statistically significant differences in the loss modulus were observed between fresh control and $20 \% \mathrm{CPA}$ at $0.2 \mathrm{~Hz}(p=0.049)$, $0.5 \mathrm{~Hz}(p=0.02)$, and $2 \mathrm{~Hz}(p=0.035)$.

\section{Compression testing}

The stiffness of the fresh control and different CPA concentration treatment groups are presented in Fig. 5. The mean stiffness of the fresh control group was $229.14 \mathrm{~N} / \mathrm{mm}$ $( \pm \mathrm{SEM}=34.49 \mathrm{~N} / \mathrm{mm}), 0 \%$ CPA group was $296.35 \mathrm{~N} /$ 


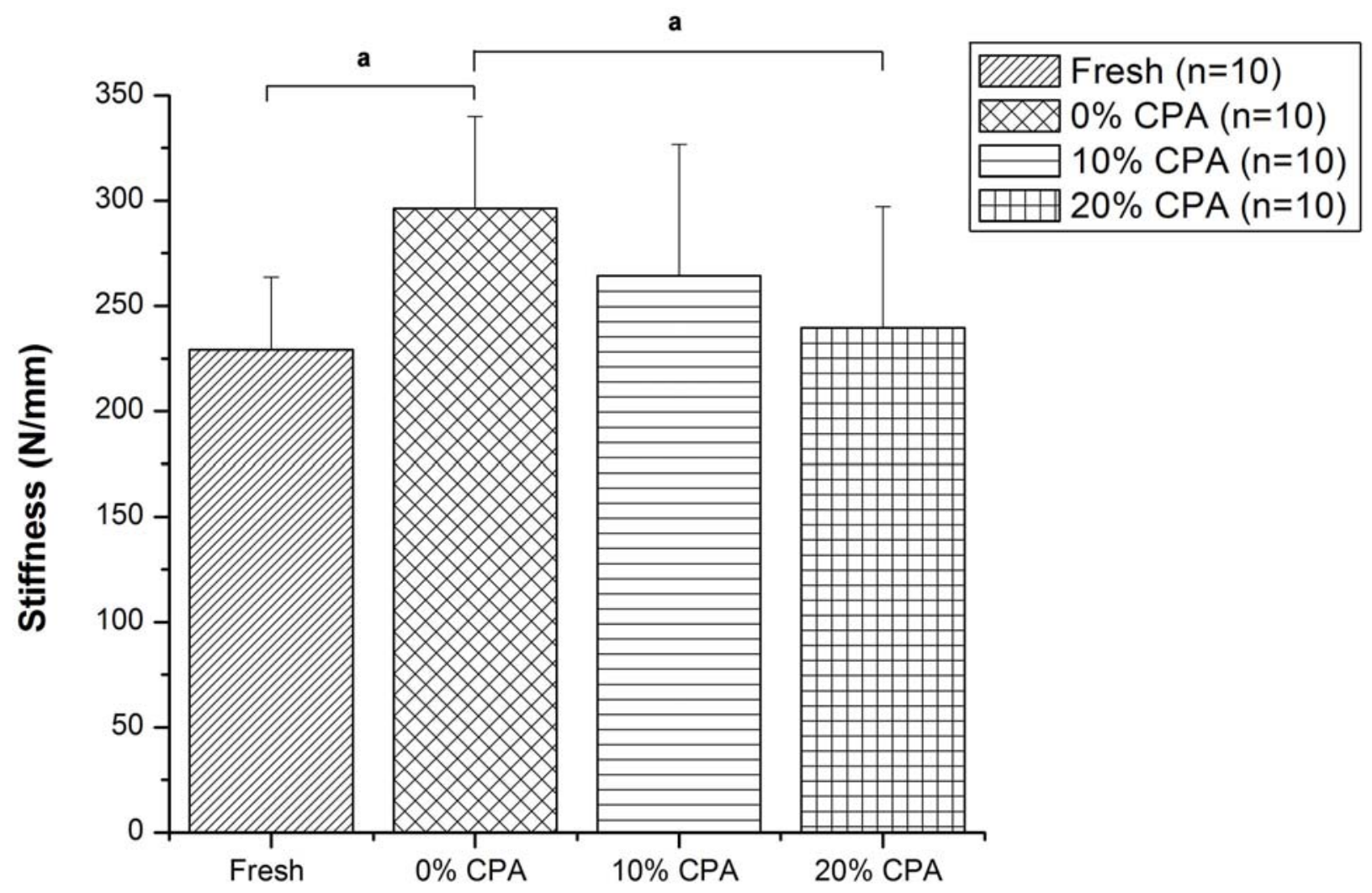

Fig. 5. Effects of cryopreservation (CPA) concentration on the (a) complex modulus $\left(\mathrm{G}^{*}\right)$, (b) elastic modulus ( $\left.\mathrm{G}^{\prime}\right)$, (c) viscous modulus $\left(\mathrm{G}^{\prime \prime}\right)$, and the (d) loss tangent $\left(\mathrm{G}^{\prime \prime} / \mathrm{G}^{\prime}\right)$ of the porcine intervertebral disc (mean $\left.\pm \mathrm{SEM}\right){ }^{\mathrm{a}}=p<$ 0.05, $0 \%$ CPA vs. $20 \%$ CPA. $^{\mathrm{b}}=p<0.05$, Fresh vs. $20 \%$ CPA.

$\mathrm{mm}( \pm \mathrm{SEM}=43.70 \mathrm{~N} / \mathrm{mm}), 10 \% \mathrm{CPA}$ was $264.17 \mathrm{~N} / \mathrm{mm}$ $( \pm \mathrm{SEM}=62.60 \mathrm{~N} / \mathrm{mm})$ and $20 \% \mathrm{CPA}$ was $239.63 \mathrm{~N} / \mathrm{mm}$ $( \pm \mathrm{SEM}=57.50 \mathrm{~N} / \mathrm{mm})$. Post-hoc test showed statistical significant differences in the apparent modulus between the fresh control and the $0 \%$ CPA group $(p=0.007)$. Statistically significant differences were also detected between the $20 \%$ CPA group and the $0 \%$ CPA group ( $p$ $=0.021)$. No significant differences were found between the fresh control and the $20 \%$ CPA group $(p=0.659)$ as well as the $10 \%$ CPA group $(p=0.145)$. Also, no statistical significant difference was noted between the $10 \%$ CPA group and the $20 \%$ CPA group ( $p=0.304$ ).

\section{Discussion}

The IVD is a viscoelastic tissue consisting of a proteoglycanrich nucleus pulposus surrounded by a collagenous annulus fibrosus (Palmer and Lotz, 2004), and it retains its mechanical nature due to its ability to attract and retain water (Bass et al., 1997; Maclean et al., 2004; Miyamoto et $a l ., 2006)$. The proteoglycans within the nucleus pulposus act to absorb water and osmotically exert a swelling pressure that enables it to resist the compressive loads (Farfan et al., 1972; Urban and Maroudas, 1981; Urban and McMullin, 1985; Urban and McMullin, 1988; Roberts et al., 1996; Urban et al., 1998). Some authors have reported that frozen IVD has significantly less swelling pressure than fresh IVDs (Keller et al., 1990; Johnstone et al., 1992; Bass et al., 1997). Given that the swelling pressure directly affects the mechanical behaviour of the disc, it was believed that cryopreserving the IVD without CPA may result in the IVD having less capacity to absorb water and thus less swelling pressure; thereby, causing the frozen IVD to be more rigid and more viscous (Johnstone et al., 1992; Buckwalter et al., 1993; Bass et al., 1997). In the current study, the authors tested the IVD allograft when it was cryopreserved under different concentrations of $0 \% \mathrm{CPA}, 10 \% \mathrm{CPA}$ and $20 \% \mathrm{CPA}$. Increased viscous modulus was observed in the $0 \%$ CPA group, which was consistent with results in the literature looking at the effects of freezing the IVD (Keller et al., 1990; Bass et al., 1997). This increase in viscous modulus in IVDs without CPA was very similar in characteristic to degenerated or injured IVD and is believed to be related to the dehydration of the nucleus, which then was unable to bind water and generate swelling pressure (Farfan et al., 1972; Holm et al., 1981; Keller et al., 1990; Bass et al., 1997). Also, it has been reported that the dehydration of tissue during the freezing process can cause the increase in cross-linking of collagen fibrils leading to increased stiffness of tissues (Yannas and Tobolsky, 1967; Weadock et al., 1984; Dahl et al., 2006). Frozen IVDs may become dehydrated when water travels from the collagen fibrils to sites of ice crystal nucleation, thereby increasing cross-linking between collagen fibrils. This increase in cross-linking from dehydration may 
contribute to the higher stiffness of IVDs cryopreserved with $0 \%$ CPA than fresh IVDs (Dahl et al., 2006). IVDs preserved with $10 \%$ and $20 \%$ CPA showed viscous characteristics similar to that of the fresh control discs, suggesting that the CPA had the ability to deter dehydration of the nucleus through substitution of water in the cells with the CPA and minimise damage caused by the ice formation during the freezing process as well as retaining its ability to bind and absorb water during the thawing process following cryopreservation (Brockbank et al., 2000; Song et al., 2004; Pegg, 2007).

Moreover, cryopreserved IVDs which can retain similar mechanical properties and functions to attenuating shocks as well as distributing loads as of fresh IVDs can avert any issues relating to the mismatch of mechanical properties between the implant and the host tissue as observed in artificial disc implants (Bao et al., 1996). Studies have shown that the difference in mechanical properties between implants and the host tissue may change the pattern of loading through the spine and can cause changes to the kinematics as well as degeneration of the facet joints. (Dooris et al., 2001; Rundell et al., 2008; Rohlmann et al., 2009). Results demonstrate that the cryopreserved IVD allografts with CPA retained similar stiffness to the fresh IVD suggesting that there may not be a mismatch of mechanical properties following transplantation. Therefore, the cryopreserved IVD allografts should be able to attenuate shocks and distribute loads as of normal IVD following transplantation.

It has also been suggested that freezing can induce changes to the characteristics of the proteoglycans within the IVD and these changes were similar to those observed in aged IVDs, which have limited capacity to swell (Keller et al., 1990; Buckwalter et al., 1993; Bass et al., 1997). While in previous studies of IVD cryopreservation, Chan et al. (2010) observed that IVDs cryopreserved with CPA showed positive safranin $\mathrm{O}$ orange staining demonstrating that the cryopreservation process was able to preserve proteoglycan content within the NP area comparable to the fresh control IVD, suggesting that the cryopreserved IVDs maintained the capacity to bind water. Furthermore, Matsuzaki et al. (1996) concluded that storage duration had little impact on cell viability in the intervertebral disc and matrix synthesis, however, thermal stresses that developed during the cooling and thawing procedure may cause fractures in the tissue structure (Pegg et al., 1997). The authors believe that the precise and delicate cooling, and thawing protocol applied in this study can prevent the occurrence of these fractures as histological studies of cryopreserved IVD from previous studies confirmed that the overall matrix organisation was maintained following cryopreservation with the same cryopreservation protocol. Sections of the cryopreserved IVD showed that the AF structure stayed in an organised manner when cryopreserved with CPA, however, Chan et al. (2010) did noticed the formation fissures between AF fibres indicating traces of ice formation during the freeze/thaw process (Chan et al., 2010). The combination of CPA with step-wise freezing protocol can prevent cell death associated with freezing and reduce ice crystal formation, which might potentially reduce the disruption of the IVD structure postcryopreservation (Bass et al., 1997; Dhillon et al., 2001).

Cell death during the freezing process may also affect the mechanical behaviour indirectly because of the degradative enzymes that are released from the dying cells in the extracellular matrix. Bass et al. (1997) suggested that these degradative enzymes may have deleterious effects on the tissue proteoglycans; thus, affecting the disc's osmotic pressure and its capacity to swell. Gleizes et al. (1998) concluded that freezing the IVD produces a dysfunction of cell metabolism, which includes modification of intra-cellular $\mathrm{pH}$ and release of proteolytic enzymes, which may lead to the formation of extracellular ice and the development of cytolysis. This combinational effect of cytolysis and catalytic enzymes in the extracellular environment leads to a decrease in proteoglycans, which induces a fall in osmotic pressure within the disc. (Gleizes et al., 1998) Since the value of the osmotic pressure directly governs the stiffness of the disc, the biomechanical properties also alter accordingly. In a previous study concerning the cryopreservation of the IVD performed by the authors, it was concluded that the use of $20 \%$ CPA provided the most ideal condition in contributing to cell viability following cryopreservation (Chan et al., 2010). Both the metabolic activity analysis and the safranin $\mathrm{O}$ histological evaluation suggests that the CPA have penetrated through the disc into both the AF and NP areas and preserved proteoglycan levels comparable to the fresh IVDs. We propose that the use of CPA may retain the mechanical properties of the IVD following cryopreservation through preserving disc cell viability, thereby maintaining the integrity of extracellular matrix and hence the capacity of IVD to absorb water to sustain intradiscal osmotic pressure.

The loss tangent shows that the elastic modulus is more dominant over the viscous modulus suggesting that the IVD allograft behaved similar to the normal intact disc where it exhibited more elastic behaviour during compression. A significant difference in the loss tangent between the 20 $\%$ CPA and the fresh control suggests that the $20 \% \mathrm{CPA}$ group is more elastic in behaviour during compression. When the IVD is compressed, the pressure in the hydrated NP expands out radially and places the collagen fibres in the $\mathrm{AF}$ under tension and resists further nuclear expansion providing equilibrium. For all the discs, the decreasing trend observed in the loss modulus with increasing frequency indicates that the viscous behaviour of the cryopreserved IVD allograft is most prominent at the lower frequency suggesting that the NP acts more to resist compressions at lower frequency while at higher frequencies the AF is stretched and plays a more dominant role in resisting compression. Results also show that the elastic moduli as well as the viscous modulus are parameters that are highly dependent on frequency. (Kim et al., 1995; Miyamoto et al., 2006) Preliminary tests showed that results at higher frequencies beyond $1 \mathrm{~Hz}$ have plateaued and it is believed that the data for $1.5 \mathrm{~Hz}$ will not be significantly different. Therefore, this study only tested the IVD up to a frequency of $2 \mathrm{~Hz}$. The authors believe that the dynamic viscoelastic testing used in this study can effectively provide insights 
into the biomechanical properties of the IVD because of its sensitivity and ability to adapt a broad range of load frequencies (Tanaka et al., 2002), and have used dynamic viscoelastic testing to simulate physiological loading of the IVD and demonstrated the nonlinear behaviour of the IVD tissue as well as its dependency on frequency of load (Beek et al., 2001).

In this study, porcine lumbar discs were used as a model because their sizes are comparable to that of the human cervical discs (Lu et al., 1999). In a study comparing the mechanical properties of glycosaminoglycans and water contents of seven different mammalian species, it was suggested that the disc tissue properties were mostly similar across animal species including pig and human (Beckstein et al., 2008). Furthermore, the porcine lumbar disc model has been used in previous studies looking at disc mechanics and its properties were comparable to the human IVD in terms of axial mechanics, glycosaminoglycans and water content (Bass et al., 1997; Reno et al., 1997). However, adolescent pig discs have notochordal cells (Zhao et al., 2006). Considering that notochordal cells produce matrices of different composition to that of the chondrocyte-like cells (Horner et al., 2002; Kim et al., 2003; Roughley, 2004), the cryopreservation of human IVDs will be different. Therefore, whether our findings can apply to human discs necessitates future assessment. Nevertheless, this study verified the effects of different cryopreservant conditions and forms the basis for future cryopreservation and IVD tissue banking protocols assessments.

\section{Conclusions}

To the authors's knowledge, this is the first study to assess the effects of CPA on the mechanical properties of the IVD following cryopreservation. We show that in disc cryopreservation, preservation of the mechanical properties of IVD may be achieved through the use of CPAs. Our findings provide further credence for the application of long-term storage and establishment of tissue banking protocols in support of IVD allografts for disc transplantation or tissue engineered constructs for the treatment of severe DDD.

\section{Acknowledgments}

The project was supported by The University of Hong Kong: CRCG grant and Tam Sai Kit Endowment Fund. The authors wish to thank Dr. Dino Samartzis for his assistance with the preparation of this manuscript and Mr Stephen Chan for his help in the mechanical testing.

\section{References}

Andersson GB (1999) Epidemiological features of chronic low-back pain. Lancet 354: 581-585.

Bao Q, McCullen G, Higham P, Dumbleton J, Yuan H (1996) The artificial disc: Theory, design and materials. Biomaterials 17: 1157-1167.
Bass E, Duncan N, Hariharan J, Dusick J, Bueff H, Lotz J (1997) Frozen storage affects the compressive creep behavior of the porcine intervertebral disc. Spine 22: 28672876.

Beckstein JC, Sen S, Schaer TP, Vresilovic EJ, Elliott DM (2008) Comparison of animal discs used in disc research to human lumbar disc: Axial compression mechanics and glycosaminoglycan content. Spine 33: E166-E173.

Beek M, Aarnts MP, Koolstra JH, Feilzer AJ, van Eijden TM (2001) Dynamic properties of the human temporomandibular joint disc. J Dent Res. 80: 876-880.

Bendix T, Kjaer P, Korsholm L (2008) Burned-out discs stop hurting: Fact or fiction? Spine 33: E962-967.

Brockbank KG, Lightfoot FG, Song YC, Taylor MJ (2000) Interstitial ice formation in cryopreserved homografts: A possible cause of tissue deterioration and calcification in vivo. J Heart Valve Dis 9: 200-206.

Brox J, Sørensen R, Friis A, Nygaard Ø, Indahl A, Keller A, Ingebrigtsen T, Eriksen H, Holm I, Koller A, Riise R, Reikerås O (2003) Randomized clinical trial of lumbar instrumented fusion and cognitive intervention and exercises in patients with chronic low back pain and disc degeneration. Spine 28: 1913-1921.

Buckwalter JA, Woo SL, Goldberg VM, Hadley EC, Booth F, Oegema TR, Eyre DR (1993) Soft-tissue aging and musculoskeletal function. J Bone Joint Surg Am 75: 1533-1548.

Chan SCW, Lam SKL, Leung VYL, Chan D, Luk KDK, Cheung KMC (2010) Minimizing cryopreservationinduced loss of disc cell activity for storage of whole intervertebral discs. Eur Cell Mater 19: 273-283.

Costi J, Hearn T, Fazzalari N (2002) The effect of hydration on the stiffness of intervertebral discs in an ovine model. Clin Biomech (Bristol, Avon). 17: 446-455.

Dahl SL, Chen Z, Solan AK, Brockbank KG, Niklason LE, Song YC (2006) Feasibility of vitrification as a storage method for tissue-engineered blood vessels. Tissue Eng 12: 291-300.

de Schepper E, Damen J, van Meurs JB, Ginai AZ, Popham M, Hofman A, Koes BW, Bierma-Zeinstra SM (2010) The association between lumbar disc degeneration and low back pain: The influence of age, gender, and individual radiographic features. Spine 35: 531-536.

Deyo RA, Mirza SK, Martin BI (2006) Back pain prevalence and visit rates: Estimates from US National surveys, 2002. Spine 31: 2724-2727.

Dhillon N, Bass EC, Lotz JC (2001) Effect of frozen storage on the creep behavior of human intervertebral discs. Spine 26: 883-888.

Dooris AP, Goel VK, Grosland NM, Gilbertson LG, Wilder DG (2001) Load-sharing between anterior and posterior elements in a lumbar motion segment implanted with an artificial disc. Spine 26: E122-129.

Farfan HF, Huberdeau RM, Dubow HI (1972) Lumbar intervertebral disc degeneration: The influence of geometrical features on the pattern of disc degeneration $-\mathrm{a}$ post mortem study. J Bone Joint Surg Am 54: 492-510.

Flynn J, Rudert M, Olson E, Baratz M, Hanley E (1990) The effects of freezing or freeze-drying on the 
biomechanical properties of the canine intervertebral disc. Spine 15: 567-570.

Freburger J, Holmes G, Agans R, Jackman A, Darter J, Wallace A, Castel L, Kalsbeek W, Carey T (2009) The rising prevalence of chronic low back pain. Arch Intern Med. 169: 251-258.

Frick S, Hanley EJ, Meyer RJ, Ramp W, Chapman T (1994) Lumbar intervertebral disc transfer. A canine study. Spine 19: 1862-1834.

Fritzell P, Hägg O, Wessberg P, Nordwall A, Group. SLSS (2001) 2001 Volvo award winner in clinical studies: Lumbar fusion versus nonsurgical treatment for chronic low back pain: A multicenter randomized controlled trial from the Swedish lumbar spine study group. Spine 26: 2521-2532.

Gantenbein B, Grunhagen T, Lee CR, van Donkelaar CC, Alini M, Ito K (2006) An in vitro organ culturing system for intervertebral disc explants with vertebral endplates: A feasibility study with ovine caudal discs. Spine 31: 2665-2673.

Ghiselli G, Wang JC, Bhatia NN, Hsu WK, Dawson EG (2004) Adjacent segment degeneration in the lumbar spine. J Bone Joint Surg Am 86: 1497-1503.

Gleizes V, Viguier E, Feron J, Canivet S, Lavaste F (1998) Effects of freezing on the biomechanics of the intervertebral disc. Surgical and radiologic anatomy 20: 403-407.

Gray DT, Deyo RA, Kreuter W (2006) Populationbased trends in volumes and rates of ambulatory lumbar spine surgery. Spine 31: 1957-1963.

Hart LG, Deyo RA, Cherkin DC (1995) Physician office visits for low back pain. Frequency, clinical evaluation, and treatment patterns from a US National survey. Spine 20: 11-19.

Hilibrand AS, Robbins M (2004) Adjacent segment degeneration and adjacent segment disease: The consequences of spinal fusion? Spine J 4: S190-S194.

Holm S, Maroudas A, Urban JP, Selstam G, Nachemson A (1981) Nutrition of the intervertebral disc: Solute transport and metabolism. Connect Tissue Res 8: 101-119.

Hoogendoorn RJ, Helder MN, Wuisman PI, Bank RA, Everts VE, Smit TH (2008) Adjacent segment degeneration: Observations in a goat spinal fusion study. Spine 33: 1337-1343.

Horner HA, Roberts S, Bielby RC, Menage J, Evans H, Urban JP (2002) Cells from different regions of the intervertebral disc: Effect of culture system on matrix expression and cell phenotype. Spine 27: 1018-1028.

Huang RC, Girardi FP, Cammisa FPJ, Wright TM (2003) The implications of constraint in lumbar total disc replacement. Journal of Spinal Disorders and Techniques. 16: 412-417.

Johnstone B, Urban JP, Roberts S, Menage J (1992) The fluid content of the human intervertebral disc. Comparison between fluid content and swelling pressure profiles of discs removed at surgery and those taken postmortem. Spine 17: 412-416.

Katz J (2006) Lumbar disc disorders and low-back pain: Socioeconomic factors and consequences. J Bone Joint Surg Am 88: 21-24.
Keller TS, Holm SH, Hansson TH, Spengler DM (1990) 1990 Volvo award in experimental studies. The dependence of intervertebral disc mechanical properties on physiologic conditions. Spine 15: 751-761.

Kim KW, Lim TH, Kim JG, Jeong ST, Masuda K, An HS (2003) The origin of chondrocytes in the nucleus pulposus and histologic findings associated with the transition of a notochordal nucleus pulposus to a fibrocartilaginous nucleus pulposus in intact rabbit intervertebral discs. Spine 28: 982-990.

Kim YJ, Bonassar LJ, Grodzinsky AJ (1995) The role of cartilage streaming potential, fluid flow and pressure in the stimulation of chondrocyte biosynthesis during dynamic compression. J Biomech 28: 1055-1066.

Lee CK, Goel VK (2004) Artificial disc prosthesis: Design concepts and criteria. Spine J 4: S209-S218.

Lee CK, Langrana NA (2004) A review of spinal fusion for degenerative disc disease: Need for alternative treatment approach of disc arthroplasty? Spine J 4: S173-S176.

Lu J, Ebraheim NA, Yang H, Rollins J, Yeasting RA (1999) Anatomic bases for anterior spinal surgery: Surgical anatomy of the cervical vertebral body and disc space. Surgical and Radiologic Anatomy 21: 235-239.

Luk KD, Ruan DK (2008) Intervertebral disc transplantation: A biological approach to motion preservation. Eur Spine J. 17: 504-510.

Luk KDK, Ruan DK, Lu DS, Fei ZQ (2003) Fresh frozen intervertebral disc allografting in a bipedal animal model. Spine 28: 864-869.

Luoma K, Riihimaki H, Luukkonen R, Raininko R, Viikari-Juntura E, Lamminen A (2000) Low back pain in relation to lumbar disc degeneration. Spine 25: 487-492.

Maclean JJ, Lee CR, Alini M, Iatridis JC (2004) Anabolic and catabolic mrna levels of the intervertebral disc vary with the magnitude and frequency of in vivo dynamic compression. J Orthop Res 22: 1193-1200.

Matsuzaki H, Wakabayashi K, Ishihara K, Ishikawa H, Ohkawa A (1996) Allografting intervertebral discs in dogs: A possible clinical application. Spine 21: 178-183.

Miyamoto K, Masuda K, Kim JG, Inoue N, Akeda K, Andersson GB, An HS (2006) Intradiscal injections of osteogenic protein-1 restore the viscoelastic properties of degenerated intervertebral discs. Spine J 6: 692-703.

Olson E, Hanley EJ, Rudert M, Baratz M (1991) Vertebral column allografts for the treatment of segmental spine defects. An experimental investigation in dogs. Spine 16: 1081-1088.

Palmer EI, Lotz JC (2004) The compressive creep properties of normal and degenerated murine intervertebral discs. J Orthop Res 22: 164-169.

Park P, Garton HJ, Gala VC, Hoff JT, McGillicuddy JE (2004) Adjacent segment disease after lumbar or lumbosacral fusion: Review of the literature. Spine 29: 1938-1944.

Pegg DE (2007) Principles of cryopreservation. Methods Mol Biol 368: 39-57.

Pegg DE, Wusteman MC, Boylan S (1997) Fractures in cryopreserved elastic arteries. Cryobiology 34: 183-192. 
Reno C, Marchuk L, Sciore P (1997) Rapid isolation of total RNA from small samples of hypocellular, dense connective tissues. Biotechniques 22: 1082-1086.

Roberts S, Urban JP, Evans H, Eisenstein SM (1996) Transport properties of the human cartilage endplate in relation to its composition and calcification. Spine 21: 415-420.

Rohlmann A, Mann A, Zander T, Bergmann G (2009) Effect of an artificial disc on lumbar spine biomechanics: A probabilistic finite element study. Eur Spine J 18: 89-97.

Roughley PJ (2004) Biology of interverterbral disc aging and degeneration. 2923.

Ruan D, He Q, Ding Y, Hou L, Li J, Luk KD (2007) Intervertebral disc transplantation in the treatment of degenerative spine disease: A preliminary study. Lancet 369: 993-999.

Rundell SA, Auerbach JD, Balderston RA, Krutz SM (2008) Total disc replacement positioning affects facet contact forces and vertebral body strains. Spine 33: 25102517.

Song YC, An YH, Kang QK, Li C, Boggs JM, Chen Z, Taylor MJ, Brockbank KG (2004) Vitreous preservation of articular cartilage grafts. J Invest Surg 17: 65-70.

Tanaka E, Aoyama J, Tanaka M, Murata H, Hamada T, Tanne K (2002) Dynamic properties of bovine temporomandibular joint disks change with age. J Dent Res. 81: 618-622.

Tournier C, Aunoble S, Le Huec J, Lemaire J, Tropiano P, Lafage V, Skalli W (2007) Total disc arthroplasty: Consequences for sagittal balance and lumbar spine movement. Eur Spine J. 16: 411-421.

Urban JP, Maroudas A (1981) Swelling of the intervertebral disc in vitro. Connect Tissue Res 9: 1-10.

Urban JP, McMullin JF (1985) Swelling pressure of the inervertebral disc: Influence of proteoglycan and collagen contents. Biorheology 22: 145-157.

Urban JP, McMullin JF (1988) Swelling pressure of the lumbar intervertebral discs: Influence of age, spinal level, composition, and degeneration. Spine 13: 179-187.

Urban MR, Fermor B, Lee RB, Urban JP (1998) Measurement of DNA in intervertebral disc and other autofluorescent cartilages using the dye hoechst 33258 . Anal Biochem 262: 85-88.

Weadock K, Olson RM, Silver FH (1984) Evaluation of collagen crosslinking techniques. Biomater. Med. Dev. Artif. Org. 11: 293-318.
Yannas I, Tobolsky AV (1967) Cross-linking of gelatine by dehydration. Nature 215: 509-510.

Zhao CQ, Jiang LS, Dai LY (2006) Programmed cell death in intervertebral disc degeneration. Apoptosis 11: 2079-2088.

\section{Discussion with Reviewers}

Reviewer I: Dhillon et al. (2001, text reference) compared the effect of freezing before and after freezing within the same disc (within level comparison) and of two adjacent discs (between level comparison, to exclude potential artifacts. What was the reason that you did not test within one level?

Authors: All the samples were randomly pooled in a bank of IVDs for storage. We did not test within the one level before and after freezing because we followed the cryopreservation protocol established in Chan et al. (2010, text reference), where the IVDs are cryopreserved within 2 hours death of the animal to ensure that maximum cell viability was preserved. Testing the IVD before cryopreservation will compromise the results as we believed that many of the cells within the IVD will not have survived and the mechanical testing results will not reflect the effects of the cryopreservation.

Reviewer III: A figure illustrating the penetration depth of the CPAs would greatly improve the paper and many of the points being made in the discussion. Much of the discussion hinges on the understanding that the CPAs fully penetrated the discs. Is there proof of this? How different is the concentration within the disc for $10 \%$ versus $20 \%$ ? Has this been measured?

Authors: Chan et al. (2010, text reference) showed that the preservation of nucleus pulposus cell viability was achieved by using various concentrations of cryopreservants and histological studies suggesting that the cryopreservants had penetrated into the centre of the disc. We do not know the difference in the penetration between the $10 \%$ and $20 \%$ CPA and future studies directly looking at the penetration of the cryopreservant into the disc will be need to address this question. 